\title{
A Surveying Study on Social Satisfaction to Current Doctor-Patient Relationship in China
}

\author{
Jingfen Shi1,2*, Yushi Jiang1, Pei Hu1, Yong Gong2, Yuanfeng Li² \\ ${ }^{1}$ School of Economics and Business Administration, Southwest Jiaotong University, Chengdu, China \\ ${ }^{2}$ Sichuan Academy of Medical Sciences \& Sichuan Provincial People's Hospital, Chengdu, China \\ Email: stone scarlet@hotmail.com
}

Received 18 September 2015; accepted 17 October 2015; published 20 October 2015

Copyright (C) 2015 by authors and Scientific Research Publishing Inc.

This work is licensed under the Creative Commons Attribution International License (CC BY).

http://creativecommons.org/licenses/by/4.0/

(c) (i) Open Access

\begin{abstract}
Objective: To survey social satisfaction to current doctor-patient relationship and to explore the influencing factors and improvement strategy. Methods: Survey 1167 people on internet by selfregulating questionnaire within the specified time and then make a statistical analysis. Results: The public's satisfaction to doctor-patient relationship is just at the level of $51.11 \%$. And the sa-

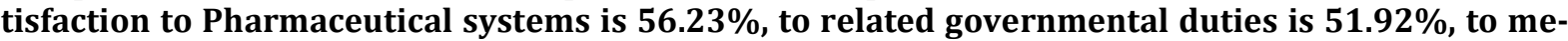
dia coverage is $59.72 \%$, to medical personnel is $65.68 \%$, to patient is $65.74 \%$. There are statistical differences between different ages, residences, educational backgrounds, occupation and medical payments $(P<\mathbf{0 . 0 5})$. Conclusion: The public's satisfaction to current doctor-patient relationship is lower. It's a system engineering to improve the doctor-patient relationship. It needs the medical personnel, patient, government and medium to participate in together and pay more effort to improve doctor-patient relationship.
\end{abstract}

\section{Keywords}

\section{Doctor-Patient Relationship, Social Satisfaction, Survey}

\section{Introduction}

Doctor-patient relationship refers to the interpersonal relationship between the medical care providers and the receivers established during the medical treatment and it is one of the core research problem of medical ethics. Narrowly, doctor-patient relationship is the specific medical care provider-receiver relationship between the doctor and the individual patient. Generally, doctor-patient relationship is the people-to-people relationship between the doctor-oriented medical personnel and the patient-oriented crowd [1]. Since doctor-patient relationship is a long-history topic and becomes the "thermometer" of social complicated contradictions. It has raised

\footnotetext{
*Corresponding author.
}

How to cite this paper: Shi, J.F., Jiang, Y.S., Hu, P., Gong, Y. and Li, Y.F. (2015) A Surveying Study on Social Satisfaction to Current Doctor-Patient Relationship in China. Journal of Service Science and Management, 8, 695-702.

http://dx.doi.org/10.4236/issm.2015.85071 
concerns from the country, people and medium. There have been many researches and discussions in domestic and foreign academia forming various theory systems and research achievements in different views [2]-[19]. In recent years, domestic doctor-patient relationship is becoming more strained with the explosion of multiform doctor-patient crisis events with high risk, high attention and wide spread and it turns to be the tendency. On March 16, 2012, the event made a sensation throughout the country that about 40 medical personnel of Shanxi Hengshan Baixin Hospital all kneeled down to their patients; on March 23, 2012, the murder happened in the First Affiliated Hospital of Harbin Medical University; on February 26, 2014, Weibo reported that a nurse of Nanjing Stomatological hospital Medical School of Nanjing University was hit by a pair of state cadre couple and got spinal cord injury and paralysis of two lower limbs, also arising the hot discussion in the nation; and on April 1, 2015, Zhou Xiaohui who was the chief physicians in the department of hepatobiliary surgery of Sichuan Provincial People's Hospital suffered from the medical disputes and hung himself... Doctor-patient relationship has been the topic discussed in all circles and the focus of research in medical academia.

On the basis of the references to pertinent literature, the thesis combined the current conditions and characteristics of domestic doctor-patient relationship to screen out the possible dimensions of influential elements, edit a set of questionnaire about the social satisfaction to doctor-patient relationship and survey the public about the satisfaction to the present doctor-patient relationship on the Internet.

This study subsidized by Sichuan Provincial Ministry of Health. The research project is A Research on Evaluation Model and Influential Factors of Doctor-Patient Relationship. The project number is 130,139 which can be inquired from the website www.scwst.gov.cn.

\section{Objects and Methods}

\subsection{Objects and Methods of Survey}

The questionnaire was released on the Internet by Wechat on the phone in February, 2015 and SO JUMP survey company (http://www.sojump.com) within the survey period from March $24^{\text {th }}$ in 2015 to April $8^{\text {th }}$ in 2015. According to SUN Zhen-qiu Medical Statistics, sample size should be 10 - 20 times of questionnaire items. This questionnaire items were 23, so the sample size should be 230 - 460. In consideration of the more provinces and the big population in China, we demanded the company to survey more than 1000 netizens and citizens in the different province and cities.

There were 1080 valid questionnaires from SO JUMP and 87 valid questionnaires from Wechat on the phone, not including these submitted out of date in the statistic data. Finally there were 1167 valid questionnaires. After the returned 1167 valid questionnaires were entered into the database, we used SPSS 20.0 software package to analyse the reliability and validity of the questionnaires; then we disposed the evaluation and statistics with Excel. One-element ANOVA was used to get difference analysis. To describe evaluation results, we only reported average values with standard deviation eliminated to save space; single sample $t$ test was adopted to analyse the sexual differences.

\subsection{Design of the Questionnaire}

With comprehensive applications of literature research and expert consultation and combining the domestic current situations of doctor-patient relationship and pharmaceutical system, we developed the questionnaire by ourselves. Five items were deleted with the testing of the reliability and validity of the pre-investigation and analysis of 87 Wechat Moments, thus the formal survey questionnaire was formed. Every item was counted by 7-scale Likert scale and the satisfactory option was 5 points or above. Meanwhile, formal questionnaire consisted of six dimensions and 23 items in sum, and the dimensions and their abbreviations are as following: Pharmaceutical systems (PS), governmental duties (GD), media coverage (MC), Evaluation of medical personnel (EMP), Evaluation of patient (EOP) and Evaluation of doctor-patient relationship (EDPR).

\section{Results}

\subsection{Statistical Results of Objects' General Conditions}

\subsubsection{Description of the Investigated Objects' Location}

The objects responding to the survey came from 16 provinces in the country and locations of samples were shown in Figure 1. 


\section{Analysis of Location}

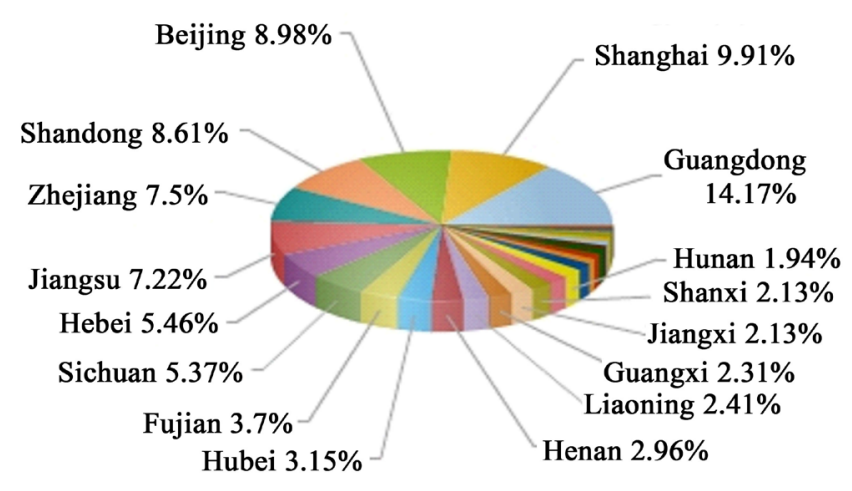

Figure 1. Location pie of investigated samples.

\subsubsection{Descriptive Statistics of Survey Objects}

Among the sample group of 1167 investigated objects, there were 565 males (48.43\%) and 602 females (51.57\%); distribution of age groups: $0.83 \%$ below $20 \%$, $73.24 \%$ from $20 \%$ to $35 \%, 23.7 \%$ from 36 - 50, $1.57 \%$ from 51 - 60 and $0.65 \%$ above 60 ; distribution of residence: $82.41 \%$ in cities, $10.74 \%$ in villages and towns, $6.85 \%$ in the countryside; distribution of education background: $0.09 \%$ of primary school, $0.65 \%$ of middle school, $13.33 \%$ of high school/technical secondary school/junior college/professional high school, $78.61 \%$ of bachelor degree and $7.31 \%$ of master and doctor; distribution of professional categories: $20.82 \%$ workers, $0.26 \%$ peasants, $6.43 \%$ professionals, $17.24 \%$ business or individual operater, $11.40 \%$ teachers, $6.68 \%$ medical personnel, $18.08 \%$ scientific and technicial workers, $7.88 \%$ official, $10.71 \%$ others (such as students etc.); distribution of medical payment: 61.11\% insurrances for urban employees, 11.2\% insurrances of NCMS (New Cooperative Medical Scheme), 15\% insurrances for urban residents, 3.24\% commercial insurrances, $4.07 \%$ self-paying, $3.24 \%$ at pubic expense and $2.13 \%$ others (such as students' group insurrance etc.). Group distributions of investigated objects complied with the structural characteristics of people and netizens at present.

\subsection{Satisfaction Statistics of Survey Objects}

The satisfaction rate of survey objects is the rate of objects whose evaluation scores were 5 or above. The satisfaction rates to current Pharmaceutical systems (PS), governmental duties (GD), media coverage (MC), Evaluation of medical personnel (EMP), Evaluation of patient (EOP) and Evaluation of doctor-patient relationship (EDPR) are 56.23\%, 51.92\%, 59.72\%, 65.68\%, 65.74\% and 51.11\%, respectively. $67.59 \%$ of objects held the opinion that medical personnel should take the main responsibility of building harmonious doctor-patient relationship, $68.89 \%$ thought it should be the government and $46.11 \%$ thought it should be the patient.

\subsection{Classified Statistics of Sample Group's Evaluation to the Doctor-Patient Relationship Satisfaction}

\subsubsection{Satisfactory Evaluation of Different Sexual Publics}

The evaluation scores of the publics on Pharmaceutical systems (PS), governmental duties (GD), media coverage (MC), Evaluation of medical personnel (EMP), Evaluation of patient (EOP) and Evaluation of doctor-patient relationship (EDPR) were all below 5 and generally it was inclined to be from neutrality to satisfaction. Whereas, evaluations of publics of different genders were not significantly different $(P>0.05)$. The statistical analysis results are shown in Table 1.

\subsubsection{Satisfactory Evaluation of Different Age Groups}

As it is in Table 2, no evaluation of the public on the six dimensions reached 5 points and the differences of publics of different ages on the evaluation of Pharmaceutical systems (PS), governmental duties (GD), media coverage (MC), Evaluation of medical personnel(EMP), Evaluation of patient (EOP) and Evaluation of doctorpatient relationship (EDPR) were significant $(\mathrm{P}<0.05)$. Apparently, the evaluation of the 51 - 60 group on governmental duties (GD) and doctor-patient relationship is lower than that of other groups, and the evaluation of 
Table 1. Statistical results of satisfactory evaluation of different sexual publics.

\begin{tabular}{ccccccc}
\hline Gender & $\begin{array}{c}\text { Pharmaceutical } \\
\text { systems (PS) }\end{array}$ & $\begin{array}{c}\text { Governmental } \\
\text { duties (GD) }\end{array}$ & $\begin{array}{c}\text { Media coverage } \\
\text { (MC) }\end{array}$ & $\begin{array}{c}\text { Evaluation of medical } \\
\text { personnel(EMP) }\end{array}$ & $\begin{array}{c}\text { Evaluation of } \\
\text { patient (EOP) }\end{array}$ & $\begin{array}{c}\text { Evaluation of doctor-patient } \\
\text { relationship (ERDP) }\end{array}$ \\
\hline Totality & 4.4397 & 4.2316 & 4.524 & 4.8156 & 4.7992 & 4.2738 \\
Male & 4.3954 & 4.1929 & 4.5795 & 4.7726 & 4.8562 & 4.2386 \\
Female & 4.4788 & 4.2657 & 4.475 & 4.8535 & 4.7489 & 4.3048 \\
T value & -1.153 & -0.867 & 1.232 & -1.265 & 1.617 & -0.757 \\
P value & 0.249 & 0.386 & 0.218 & 0.206 & 0.106 & 0.449 \\
\hline
\end{tabular}

Table 2. Statistical results of satisfactory evaluation of different age groups.

\begin{tabular}{ccccccc}
\hline Age & $\begin{array}{c}\text { Pharmaceutical } \\
\text { systems (PS) }\end{array}$ & $\begin{array}{c}\text { Governmental } \\
\text { duties (GD) }\end{array}$ & $\begin{array}{c}\text { Media coverage } \\
\text { (MC) }\end{array}$ & $\begin{array}{c}\text { Evaluation of medical } \\
\text { personnel (EMP) }\end{array}$ & $\begin{array}{c}\text { Evaluation of } \\
\text { patient (EOP) }\end{array}$ & $\begin{array}{c}\text { Evaluation of doctor-patient } \\
\text { relationship (ERDP) }\end{array}$ \\
\hline Below 20 & 4.5286 & 4.8 & 4.45 & 4.74 & 4.9 & 5 \\
20 - 35 & 4.4966 & 4.312 & 4.6066 & 4.8701 & 4.861 & 4.3602 \\
36 - 50 & 4.3252 & 4.0328 & 4.33 & 4.6734 & 4.6465 & 4.0286 \\
51 - 60 & 4.1429 & 3.75 & 4.1087 & 4.8087 & 4.5942 & 3.9565 \\
Above 60 & 3.4082 & 3.8929 & 4.4286 & 4.5143 & 4.4762 & 4.4286 \\
F value & 2.669 & 3.253 & 2.485 & 1.931 & 2.334 & 3.606 \\
P value & 0.031 & 0.012 & 0.042 & 0.103 & 0.054 & 0.006 \\
\hline
\end{tabular}

Table 3. Statistical results of satisfactory evaluation of publics from different residences.

\begin{tabular}{ccccccc}
\hline $\begin{array}{c}\text { Places of } \\
\text { residence }\end{array}$ & $\begin{array}{c}\text { Pharmaceutical } \\
\text { systems (PS) }\end{array}$ & $\begin{array}{c}\text { Governmental } \\
\text { duties (GD) }\end{array}$ & $\begin{array}{c}\text { Media coverage } \\
\text { (MC) }\end{array}$ & $\begin{array}{c}\text { Evaluation of medical } \\
\text { personnel (EMP) }\end{array}$ & $\begin{array}{c}\text { Evaluation of } \\
\text { patient (EOP) }\end{array}$ & $\begin{array}{c}\text { Evaluation of doctor-patient } \\
\text { relationship (ERDP) }\end{array}$ \\
\hline Urban & 4.4652 & 4.2552 & 4.5646 & 4.8315 & 4.8385 & 4.2687 \\
Towns & 4.3879 & 4.1524 & 4.4675 & 4.8049 & 4.6504 & 4.4756 \\
Countryside & 3.2245 & 4.0774 & 4.1429 & 4.65 & 4.5675 & 4.0357 \\
F value & 1.595 & 0.805 & 3.362 & 1.075 & 3.418 & 2.205 \\
P value & 0.203 & 0.447 & 0.035 & 0.342 & 0.033 & 0.111 \\
\hline
\end{tabular}

the group above 60 on the Pharmaceutical systems (PS) and governmental duties (GD) is not as high as that of other groups.

\subsubsection{Satisfactory Evaluation of Publics from Different Residences}

As it is shown in Table 3, the public satisfaction of residents from various places was not above 5 points, including that the evaluation of countryside residents is lower than that of urban and towns on media coverage(MC) and Evaluation of patient(EOP), so that the difference was statistically significant $(\mathrm{P}<0.05)$.

\subsubsection{Satisfactory Evaluation of Publics with Different Education Backgrounds}

Table 4 shows that there were significant differences among the satisfaction to each dimension of public with different education backgrounds $(\mathrm{P}=0.00)$. In general, the satisfaction of people at the cultural level of primary is the lowest, following is that of people at a cultural level of middle and high school. Meanwhile, the satisfaction of people with an education background of bachelor is the highest, then that of people with an education background of doctor follows.

\subsubsection{Satisfactory Evaluation of Publics with Various Professions}

The satisfactory evaluations of publics with diverse professions to every dimension are significantly different in Table $5(\mathrm{P}<0.05)$. On the whole, only the satisfaction of the peasant to each item is above 5 points, complying with the evaluation standard for satisfaction while these of groups with other professions is below five points including the lowest satisfaction from the medical personnel. The satisfaction to each dimension from medical 
Table 4. Statistical results of satisfactory evaluation of publics with different education backgrounds.

\begin{tabular}{ccccccc}
\hline Education background & $\begin{array}{c}\text { Pharmaceutical } \\
\text { systems (PS) }\end{array}$ & $\begin{array}{c}\text { Governmental } \\
\text { duties (GD) }\end{array}$ & $\begin{array}{c}\text { Media coverage } \\
\text { (MC) }\end{array}$ & $\begin{array}{c}\text { Evaluation of } \\
\text { medical personnel } \\
\text { (EMP) }\end{array}$ & $\begin{array}{c}\text { Evaluation of } \\
\text { patient (EOP) }\end{array}$ & $\begin{array}{c}\text { Evaluation of } \\
\text { doctor-patient } \\
\text { relationship } \\
\text { (ERDP) }\end{array}$ \\
\hline $\begin{array}{c}\text { Primary } \\
\text { Middle school }\end{array}$ & 3 & 2.75 & 3.25 & 4.4 & 3.5 & 4 \\
$\begin{array}{c}\text { High school (technical } \\
\text { secondary school/junior } \\
\text { college/professional high } \\
\text { school) }\end{array}$ & 4.9365 & 3.5278 & 3.6667 & 4.7111 & 4.1111 & 3.5556 \\
$\begin{array}{c}\text { Bachelor degree } \\
\text { Master and doctor }\end{array}$ & 4.1058 & 3.8194 & 4.1914 & 4.5506 & 4.4733 & 4.0216 \\
F value & 4.2355 & 3.6351 & 4.018 & 4.4306 & 4.3514 & 3.6441 \\
P value & 6.217 & 12.521 & 8.803 & 8.476 & 12.4 & 9.451 \\
\hline
\end{tabular}

Table 5. Statistical results of satisfactory evaluation of publics with various professions.

\begin{tabular}{ccccccc}
\hline Profession & $\begin{array}{c}\text { Pharmaceutical } \\
\text { systems } \\
\text { (PS) }\end{array}$ & $\begin{array}{c}\text { Governmental } \\
\text { duties } \\
\text { (GD) }\end{array}$ & $\begin{array}{c}\text { Media } \\
\text { coverage } \\
\text { (MC) }\end{array}$ & $\begin{array}{c}\text { Evaluation of } \\
\text { medical personnel } \\
\text { (EMP) }\end{array}$ & $\begin{array}{c}\text { Evaluation of } \\
\text { patient (EOP) }\end{array}$ & $\begin{array}{c}\text { Evaluation of } \\
\text { doctor-patient } \\
\text { relationship } \\
\text { (ERDP) }\end{array}$ \\
\hline Workers & 4.4539 & 4.3179 & 4.749 & 4.907 & 4.9986 & 4.3374 \\
Peasants & 5.5238 & 5.3333 & 5.3333 & 5.3333 & 5.4444 & 5.3333 \\
Professionals & 4.4533 & 4.3867 & 4.7533 & 4.8907 & 4.9067 & 4.4867 \\
Business or individual operators & 4.4155 & 4.2669 & 4.6087 & 4.8667 & 4.847 & 4.3575 \\
Teachers & 4.4919 & 4.265 & 4.5977 & 4.7459 & 4.9098 & 4.3233 \\
Medical personnel & 4.0861 & 3.1442 & 2.6218 & 4.1256 & 3.4103 & 3.1603 \\
Scientific and technical workers & 4.6202 & 4.4491 & 4.7938 & 4.9346 & 5.0284 & 4.4573 \\
Officials & 4.5559 & 4.337 & 4.6304 & 4.9217 & 4.7971 & 4.3533 \\
Others (such as students etc.) & 4.1931 & 4.084 & 4.364 & 4.7216 & 4.616 & 4.132 \\
F value & 2.454 & 7.223 & 21.736 & 5.04 & 19.791 & 6.801 \\
P value & 0.012 & 0 & 0 & 0 & 0 & 0 \\
\hline
\end{tabular}

personnel is apparently lower than that of groups of other professions and especially that to media coverage is even low to 2.6218 .

\subsubsection{Satisfactory Evaluation of Publics Paying in Different Ways}

As shown in Table 6, significant differences $(\mathrm{P}<0.05)$ exist in the satisfactions to the dimensions of doctor-patient relationship in the way of various payments. In general, almost all dimensions haven't been satisfactory and only the evaluation of commercial insurance payers has exceeded 5 points. In addition, self-paying medical care gets the lowest satisfaction as the commercial insurance gets the highest satisfaction. The fact of concern is that the evaluations of medical personnel working on free medical care on governmental duties (GD) and doctor-patient relationship are distinctly lower than that of groups paying in other ways.

\section{Discussions and Suggestions}

\subsection{Creativities and Disadvantages of the Study}

Firstly, the survey was established in currently strained doctor-patient relationship, studied doctor-patient relationship in the wider views of social public instead of separate relationship between medical personnel and the patient. The research of social satisfaction was carried out with the self-regulating questionnaire focusing on the influential elements of doctor-patient relationship. Then in the aspect of survey methods, the survey was effec- 
Table 6. Statistical results of satisfactory evaluation of publics paying in different ways.

\begin{tabular}{ccccccc}
\hline Medical payment & $\begin{array}{c}\text { Pharmaceutical } \\
\text { systems } \\
\text { (PS) }\end{array}$ & $\begin{array}{c}\text { Governmental } \\
\text { duties } \\
\text { (GD) }\end{array}$ & $\begin{array}{c}\text { Media } \\
\text { coverage } \\
\text { (MC) }\end{array}$ & $\begin{array}{c}\text { Evaluation of } \\
\text { medical personnel } \\
\text { (EMP) }\end{array}$ & $\begin{array}{c}\text { Evaluation of } \\
\text { patient (EOP) }\end{array}$ & $\begin{array}{c}\text { Evaluation of } \\
\text { doctor-patient } \\
\text { relationship (ERDP) }\end{array}$ \\
\hline $\begin{array}{c}\text { Urban Employees } \\
\text { Basic Medical Insurance } \\
\text { New Cooperative }\end{array}$ & 4.4636 & 4.2406 & 4.5453 & 4.8304 & 4.8136 & 4.251 \\
$\quad \begin{array}{l}\text { Medical Scheme } \\
\text { Urban Residents Basic }\end{array}$ & 4.6643 & 4.5508 & 4.5772 & 4.9073 & 4.916 & 4.561 \\
Medical Insurance & 4.3896 & 4.2303 & 4.597 & 4.8303 & 4.8848 & 4.3545 \\
commercial insurance & 4.7421 & 4.6806 & 4.9583 & 5.4 & 5 & 4.8056 \\
self-paying medical care & 3.773 & 3.4598 & 4.1071 & 4.2214 & 4.3869 & 3.8304 \\
free medical service & 4.2597 & 3.7727 & 4.1023 & 4.5091 & 4.3788 & 3.6818 \\
others & 4.3571 & 4.2981 & 4.2308 & 4.8692 & 4.6282 & 4.25 \\
F value & 4.102 & 5.198 & 2.229 & 5.369 & 3.963 & 3.661 \\
P value & 0 & 0 & 0.038 & 0 & 0.007 & 0.001 \\
\hline
\end{tabular}

tively completed with the combination of modern information and the application of internet information tools and platforms.

The disadvantages were that the survey was carried out in a short period with small sample sizes, and social public samples were limited to netizens, which caused the unbalance to people’s structure.

\subsection{Discussions of Statistical Results of Satisfaction}

The results show that the satisfaction rate of publics to doctor-patient relationship is $51.11 \%$ and that to each affective dimensions ranges from $51.92 \%$ to $65.68 \%$. Compared with the cotemporaneous surveys on the satisfaction to patient and to medical personnel, the former is usually from $60 \%$ to $90 \%$, whereas satisfaction rate to medical personnel in literature and reports is usually between $16.6 \%$ and $50 \%$ [20]-[25]. According to the findings of empirical research by Li Bin and Ren Rongming, senior managers and doctors of public hospitals hadn't gotten what they deserved for their contributions to their work [26]. Despite of that, Liu Zimin and others discovered that the gradually increasing governmental investment failed to improve the total factor productivity by researching on the dynamic efficiency of governmental investment to health service in 2003-2009 [27]. The findings of the research showed that current doctor-patient relationship was generally dissatisfactory to publics. Meanwhile medical personnel feel more upsetting than that the patient do but they still offer rather satisfying medical service to patient. In addition, it also discovers that doctor-patient relationship is not only the directly separate interpersonal relationship between medical personnel and patient, but also the social relationship with deeply meanings, being related to the influential elements including Pharmaceutical systems (PS), governmental duties (GD), media coverage (MC), Evaluation of medical personnel (EMP) and Evaluation of patient (EOP), etc.

Comparing the differences between evaluations of various sample groups, there is no significant difference between the evaluations of distinct sexual groups; significant differences exist between the evaluations of various age groups and groups with diverse education backgrounds, which can be understood that the evaluation is affected by social experiences and education backgrounds. At the same time, different frequency of disease development at different ages can affect how often people adopt medical treatment and how they feel, so then can influence their judgments. The age group above 51 with higher frequency of disease development has lower satisfaction than other groups do; the evaluations of the countryside group to media coverage and evaluation to patient are obviously lower than these of the urban and towns group, which uncovers that there exist defects in the medium propaganda and guides to people in the countryside and reminds that the countryside residents are lack of medical knowledge but have unreasonable expectations of medical treatment; in comparison with the evaluation of other groups with various professions, the satisfaction of medical personnel is the lowest that medical personnel give the poorer evaluation to each dimension than that other groups do and even only mark 2.62 points in Likert scale to media coverage. However, since the medical personnel are directly involved in the doctor-patient relationship as the direct receiver and builder that the result is worrying and calls for deep thoughts; 
the commercial insurance receives the best satisfaction while the self-payment gets the poorest one in the comparison with evaluation of various medical payments. Whereas in reality, the customers of commercial insurance usually have high income while most of the self-paying patients belong to low-income group, which shows that the payment capability is one of the elements that can affect the satisfaction to the doctor-patient relationship. Differently, the evaluation of the patient at public service to governmental duties and the doctor-relationship is apparently poorer to that of other groups paying in other ways. This unreasonable result reveals the unbalance between the medical investment and productivity in China as well as the abuse of the socialized medicine system for some people.

\subsection{Suggestions}

The deteriorative doctor-patient relationship brings more risks to the medical relationship and decreases the work satisfaction even as well as the professional honesty which can have adverse impacts on the construction of the harmonious doctor-patient relationship, even worsen the patients' confidence on the medical personnel. The doctor-patient relationship shall be referred to carry out medical reform but the medical reform is always in charge of the government. To improve the present strained doctor-patient relationship, it is a system engineering that not only requires the medical personnel and managers to promote the medical service but also needs to innovate the pharmaceutical system, strengthen the governmental duties, improve the medium publicity and guides, perfect the hospital management and promote the confidence between medical personnel and the patient at the same time. The government must perform its duties to change the disadvantages of the medical system and form the justice health service system; both the medical personnel and the patient shall have further respects, understanding and communications; the medical service provider, medical personnel must take on the responsibilities to offer better health care service; the patients are supposed to know well about the current pharmaceutical system, have scientific comments on the treatment outcomes and rationally deal with medical disputes; media must objectively and scrupulously reports the medical disputes and emergent events to lead the public opinion in the correct view.

\section{References}

[1] Xu, S.J. and Wen, K.Q. (1999) Ethic Cyclopaedia. China Radio Film \& TV Press, Beijing, 556-557.

[2] Li, Z.G. and Leng, M.X. (2009) Doctor-Patient Relationship Research Summary. Chinese Hospital Management, 29, 40-43.

[3] Mahmud, A. (2009) Doctor-Patient Relationship. DGM-Medical Services, Apollo Hospitals Dhaka, 3, 12-14.

[4] Akerkar, S.M. and Bichile, L.S. (2004) Doctor Patient Relationship: Changing Dynamics in the Information Age. Journal of Postgraduate Medicine, 2,120-122.

[5] Bake, R. and Streatfield, J. (1995) What Type of General Practice Do Patients Prefer?: Exploration of Practice Characteristics Influencing Patient Satisfaction. The British Journal of General Practice, 45, 654-659.

[6] Roter, D. (2000) The Enduring and Evolving Nature of the Patient-Physician Relationship. Patient Education Counseling, 39, 5-15. http://dx.doi.org/10.1016/S0738-3991(99)00086-5

[7] Son, Y.Y. and Zhou, Q. (2003) A Survey of Current Situation of Conflicts between Doctors and Patients and Explore the Equilibrium between Them. Chinese Health Service Management, 2, 69-70.

[8] Yin, S. (2003) Tension and Its Causes of Relationship between the Medical and the Patient. Health Economic Research, 2, 14-16.

[9] Cao, Y.-F. and Wang, Y.-L. (2005) Discussions on the Physician-Patient Relationship Affected by the Medical Care Market in China. Medicine \& Philosophy, 26, 45.

[10] Zhao, M.-J. (2005) Overhigh Medical Payment-The Important Reason of the Tense Doctor-Patient Relationship. Medicine \& Philosophy, 2, 1 .

[11] Wang, N.-X. (2008) Nash Equilibrium Analysis of the Conflicts of the Doctor-Patient Relationship in the View of Laws. Medicine and Society, 5, 31-32.

[12] Zhao, Y.B. (2008) The Construction of the Harmonious Doctor-Patient Relationship in the View of Public Relationship. Acta Universitatis Medicinalis Nanjing (Social Science), 1, 43-45.

[13] Han, Y.-X., Wang, X.-Y., Zhang, J., et al. (2012) Analysis of Evaluation between Hospital Administrator and Medical Personnel on Doctor-Patient Relationship. Chinese Hospital Management, 1, 59-61. 
[14] Li, C.-Y. and Zhu, Y.-Y. (2011) Evaluation on the Harmony Degree of Doctor-Patient Relationship Based on GreyFuzzy Theory. Medicine \& Philosophy, 6, 31-33.

[15] Liang, Y.-Q. (2012) Research on the Current Situation and Policies of the Doctor-Patient Relationship in Top Three Hospitals in Tsitsihar. Master's Thesis, Heilongjiang University of Chinese Medicine, Harbin.

[16] Wang, J., Wang, W. and Cheng, S. (2013) History Process and Future Prospect of Doctor-Patient Relationship Management in China. Medicine and Society, 2, 72-75.

[17] Xu, X.-L. (2012) Structural Factors Affecting Physician-Patient Relationship-The H Hospital Doctor Patient Relationship Investigation as an Example. Master’s Thesis, Shenyang Normal University, Shenyang.

[18] Yue, X.-Z., Wang, L.-Y. and Mao, J.-F. (2012) Analysis of Influencing Factors of Doctor Patient Relationship Based on Interpretative Structural Modeling Method. Medical Sociology, 33, 26-28.

[19] Zhou, S. (2012) Research on the Doctor-Relationship in the View of Harmony. Hunan Normal University, Changsha.

[20] Hou, S.-T. and Zhang, Y.-K. (2012) Analysis on Patient Satisfaction Measurement Based on the Perspective of Hospital Management Improvement. Chinese Hospital Management, 32, 45-48.

[21] Shi, J.-F., Gong, Y. and Li, Y.-F. (2015) Research on the Satisfaction Rating Scale and Empirical Study of Outpatients. Chinese Health Service Management, 27, 262-267.

[22] Sun, X.-H. and Xie, G.-Q., et al. (2014) The Development and Assessment of Simple Patient Satisfaction Questionnaire. Chinese Hospital, 18, 77-80.

[23] Hou, S.-T. and Zhang, Y.-K. (2013) Research of Influencing Factors of Inpatient Satisfaction Based on PLS Path Modeling. Chinese Journal of Health Statistics, 30, 368-370.

[24] Wang, L., Zhang, X.Q. and Li, E.-C. (2014) Investigation of the Job Satisfaction among Medical Staff in 45 Hospitals in China. Medicine and Society, 27, 87-89.

[25] Luo, Z.-N. and Fang, P.-Q. (2012) Current Status of Medical Workers at County Hospitals in Hubei Province and Their Perception of the Reform. Chinese Journal of Hospital Administration, 28, 524-527.

[26] Li, B. and Ren, R.-M. (2013) The Root Causes of "Seeing a Doctor Is Difficult and Expensive"-An Empirical Research Based on the Perspective of the Social Responsibility of Public Hospital. Soft Science, 27, 59-64.

[27] Liu, Z.-M. and Zhang, X.-Z. (2012) The Dynamic Efficiency and Convergence of China Government Health Investment-Based on Modified Malmquist Index Method. Soft Science, 26, 50-56. 